\title{
Drought and root herbivory in understorey Parashorea Kurz (Dipterocarpaceae) seedlings in Borneo
}

\author{
DAN BEBBER*1, NICK BROWN $\dagger$ and MARTIN SPEIGHT $\$$ \\ *Department of Plant Sciences, University of Oxford, South Parks Road, Oxford OX1 \\ $3 R B, U K$ \\ $\dagger$ Faculty of Forestry, University of Toronto, 33 Willcocks Street, Toronto M5S 3B3, \\ Ontario, Canada \\ \$Department of Zoology, University of Oxford, South Parks Road, Oxford OX1 3PS, UK \\ (Accepted 30th September 2001)
}

\begin{abstract}
The influence of herbivory on dipterocarp seedling growth and survival in Bornean primary lowland forest understorey during and after the 1997-8 El Niño-Southern Oscillation was investigated. During the drought, a coleopteran (Scolytidae) root borer attacked dipterocarp seedlings, primarily of the genus Parashorea. Infestation was spatially heterogeneous on a large $(c .100 \mathrm{~m})$ scale. Attack rate decreased with plant vigour within infested areas. Experiments showed that root damage was fatal under drought conditions, but not after rain. Defoliation and apical meristem removal did not increase mortality. The spatio-temporal heterogeneity of herbivore outbreaks and difficulties involved in experimenting with root herbivores limit the power of such short-term investigations. However, the study shows that herbivores can cause differential mortality between species, and can therefore influence dipterocarp regeneration dynamics. The effect of herbivory depends on the plant organ attacked and interactions with other stresses such as drought. El Niño-related droughts are increasing in frequency in South-East Asian rain forests, which may lead to increased numbers of herbivore outbreaks and greater seedling mortality due to these factors.
\end{abstract}

KEY WORDS: dipterocarp seedlings, drought, El Niño, Parashorea, root herbivory, Scolytidae, Xyleborus

\section{INTRODUGTION}

The recent 1997-8 El Niño event caused widespread drought and fire across South-East Asia (Walsh \& Newbery 1999). Huge plumes of smoke from thousands of fires on Borneo and Sumatra drifted across the region for several

${ }^{1}$ Corresponding author. Email: daniel.bebber@utoronto.ca 
months (Davies \& Unam 1999). In East Kalimantan an estimated 5.2 million ha burned, of which 2.3 million ha was natural-forest concession (Hoffman et al. 1999). Dipterocarp tree mortality rates due to drought were up to 30 times higher than normal in a lowland forest in Sarawak (Nakagawa et al. 2000).

The increasing frequency of El Niño events (Walsh \& Newbery 1999) could have wide-ranging consequences for tropical forest dynamics (Markham 1998, and references therein). Forest regeneration is one important process that may be affected (Whitmore 1998), both directly through effects on plant growth and reproduction, and indirectly through factors that impact regeneration, such as herbivory (Coley 1998).

Drought stress affects almost all aspects of plant physiology, many changes leading to increased susceptibility to attack and suitability of the plant as a food source (Mattson \& Haack 1987). Increased herbivory on stressed plants has been dubbed the plant stress hypothesis (White 1974), and there are many examples of insect outbreaks in temperate forests related to drought (reviewed in Mattson \& Haack 1987), and several in the tropics (reviewed in Coley 1998). However, there are also examples of insect outbreaks unrelated to drought (Anderson 1961), and of experimental studies showing insect preference for well-watered plants (Price 1991). These apparently contradictory observations have to some extent been reconciled, since insect performance depends both on the origin of stress (natural vs. experimental) and on insect feeding guild (Koricheva et al. 1998, Schowalter et al. 1999, Waring \& Cobb 1992). Though there is considerable idiosyncracy in the behaviour of different species, boring and sucking insects generally perform best on stressed plants, whilst chewers and gallers prefer healthy plants.

The extent to which El Niño-related drought influences plant-herbivore interactions in lowland dipterocarp forest is currently unknown. In order to address this question, the relationship between drought, herbivory, and dipterocarp seedlings growing in lowland forest in Sabah was investigated during the 1997-8 El Niño.

\section{STUDY SITE}

The study was conducted in lowland dipterocarp forest of the Danum Valley Conservation Area, Sabah, East Malaysia, $5^{\circ} \mathrm{N}, 117^{\circ} \mathrm{E}$. The Conservation Area is $438 \mathrm{~km}^{2}$ in size and is surrounded by a mosaic of secondary forest at various stages of regeneration after logging. The forest lies $70 \mathrm{~km}$ inland of the east coast of Borneo, at around $200 \mathrm{~m}$ asl. The geology and soils of the region are complex and variable, and the topography is undulating with differences of 30 $50 \mathrm{~m}$ in elevation (Marsh \& Greer 1992).

\section{Climate}

The climate of the Danum Valley is documented exhaustively by Walsh \& Newbery (1999). Mean annual rainfall between 1985 and 1998 was 2669 mm, 
and mean annual temperature was $26.7^{\circ} \mathrm{C}$. The highest recorded annual rainfall was $3294 \mathrm{~mm}$ in 1995, and the lowest was $1918 \mathrm{~mm}$ recorded in the $\mathrm{El}$ Niño year of 1997 . Mean monthly temperatures range only $1.9^{\circ} \mathrm{C}$ around the annual mean, and exceed $34{ }^{\circ} \mathrm{C}$ only rarely, usually during long dry spells. Relative humidity is close to saturation at 08h00, dropping to an average of $72 \%$ at $14 \mathrm{~h} 00$.

The study was conducted in 1997 and 1998, during which time one of the strongest recorded El Niño events developed (Wolter \& Timlin 1998). In each month from June to December 1997 record-high sea surface temperatures were recorded in the eastern equatorial Pacific. Negative Southern Oscillation Index (SOI) values were recorded from March 1997 to April 1998, with the greatest anomalies in early 1998. Sea surface temperatures remained anomalously high until May 1998, when the SOI became positive (McPhaden 1999). Severe droughts affected many areas of northern Borneo during this time (Walsh \& Newbery 1999). At Danum, rainfall was below the long-term (15 y) monthly mean 95\% confidence interval for most of March 1997 to April 1998, after which it increased (Figure 1). Several months had rainfall below $100 \mathrm{~mm}$, the estimated transpirational threshold (Walsh 1996), with April 1998 having the lowest rainfall ever recorded at Danum $(11.3 \mathrm{~mm})$. Rainless or near-rainless spells totalled 139 d between March 1997 and May 1998, or 33\% of the time.

\section{MATERIALS AND METHODS}

Monitoring of wild seedlings

As part of a study on the influence of herbivory on dipterocarp seedling mortality in the forest understorey, dead seedlings were periodically harvested from several seedling populations, separated by a maximum distance of around $2 \mathrm{~km}$. Surveys were conducted over three periods: February-May 1998, AugustOctober 1998 and March-May 1999. Surveying involved searching for seedlings with wilted leaves, or the brown stems of dead seedlings that had lost their leaves. Dead seedlings were investigated for signs of herbivore damage, and dissected to discover evidence of root and stem boring.

One site ('Site 4') was further investigated to determine the relationship between attack and seedling vigour at a smaller spatial scale. A $10-\mathrm{m} \times 10-\mathrm{m}$ plot was marked out in an area of high seedling mortality, and all seedlings, alive and dead, within the plot were pulled out and investigated for evidence of insect attack. A smaller 5-m $\times 5-\mathrm{m}$ plot, at a distance of $20 \mathrm{~m}$ from the large plot, was also investigated. Seedlings were classified as healthy (no sign of wilting), partially wilted (some leaves wilted and stem alive), totally wilted (all leaves wilted and stem alive), or dead. The number of beetle bore-holes in the stem and root were counted.

Experimental investigation of drought-herbivore interactions

An experiment was conducted to determine whether seedlings were more susceptible to insect damage under drought conditions. Four suitable areas 


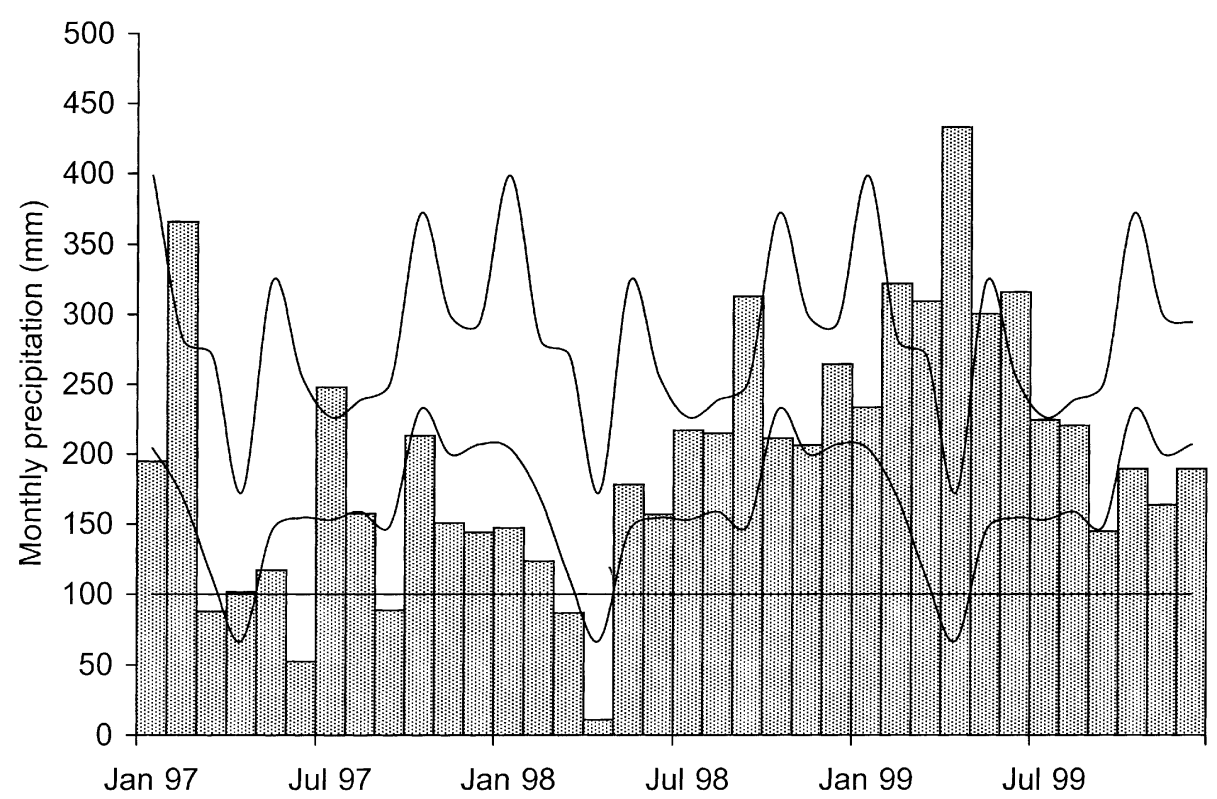

Figure 1. Danum Valley rainfall during the 1997-8 El Niño event (shaded bars), showing 95\% confidence interval of the long-term monthly means taken over 15 y (smoothed lines). Horizontal line at $100 \mathrm{~mm}$ indicates transpirational threshold. Data are from Danum Valley Field Centre records.

(blocks) were located in the forest. These areas contained high densities of Parashorea seedlings ( $>15$ seedlings $\mathrm{m}^{-2}$ ), were under intact canopy, and were separated from one another by at least $100 \mathrm{~m}$. Two common species of Parashorea, P. malaanonan (Blanco) Merr. and P. tomentella (Symington) W. Meijer, cannot be reliably distinguished as seedlings (Meijer \& Wood 1964) and so no distinction was attempted.

Within each block, two experimental plots were demarcated, separated by c. $5 \mathrm{~m}$. One plot was randomly assigned as the dry plot, the other as the wet plot. Each plot contained 32 seedlings, and was approximately $1 \mathrm{~m} \times 2 \mathrm{~m}$ in size. Only seedlings with less than $10 \%$ leaf damage were included in the study. Each seedling was tagged and numbered, and each leaf marked on the underside with a fine-tipped black indelible marker. Seedling height and leaf number were noted.

A shelter, consisting of a clear plastic corrugated roof $1 \mathrm{~m} \times 2 \mathrm{~m}$ in size, which sloped from a height of $1.5 \mathrm{~m}$ to $1.3 \mathrm{~m}$, was erected over each dry plot. The shelter roofs were swept of fallen litter weekly during the experiment to maintain light transmittance. The seedlings within each plot were randomly assigned one of three treatments or an untreated control, giving eight seedlings per treatment per plot. Leaf damage was simulated by removing the lamina on the right-hand side of the midrib with scissors. Apical damage was simulated by removing the apical meristem with scissors. The defoliation and apical damage treatments were similar to Becker (1983). Root damage was simulated 
by grasping the seedling at the base of the stem, pulling the seedling slowly out of the soil by $1 \mathrm{~cm}$ then pushing it slowly back again. The root damage treatment is unprecedented but was hypothesized to damage fine roots, since examination of uprooted seedlings showed that the tap root and major lateral roots remained intact.

Natural variation in rainfall was employed to alter soil moisture between the experimental periods for dry and wet treatments. The dry plot seedlings were first measured and treated in May 1998, and re-measured in September 1998. No shelters were erected over the wet plots, and treatments were applied in September 1998. The wet plots were re-measured in March 1999. Rainfall was very low for 2 mo prior to the first census period (Figure 1), and this was taken as the experimental period for the dry plots. Rainfall was high prior to and during the experimental period for the wet plots. Such an approach has been used previously (Coley 1998), and allows for a community-wide response as opposed to a limited experiment-scale response.

Analysis

Results from the large and small sampling plots were pooled, and differences in rates of infestation between seedling vigour categories sought using the loglinear analysis procedure of SPSS (SPSS 1999).

Relative monthly height increment (RMHI) was calculated by the difference between the $\log _{10}$ of starting and finishing height over the time between censuses. Relative monthly leaf loss (RMLL) and gain (RMLG) were calculated as the number of leaves gained and lost over the starting leaf number, divided by the time between censuses. Differences in growth were investigated using analysis of variance in a split-plot design using S-Plus (Mathsoft 2000). Differences in mortality rates between treatments were found using logit loglinear analysis (SPSS 1999).

RESULTS

Monitoring of wild seedlings

Altogether 215 dead seedlings were examined from various sites in the forest from February to May 1998 (Table 1). The seedlings were of the genus Parashorea and species Shorea johorensis Foxw. (Dipterocarpaceae). Small (approximately $1 \mathrm{~mm}$ diameter) pinholes were found in the stem or roots of $44 \%$ of the dead Parashorea seedlings, and of those with pin-holes $70 \%$ contained one or more adult beetles of the genus Xyleborus Eichoff (Coleoptera: Scolytidae). Almost a third of the attacked seedlings also contained one or more beetle larvae. Between 0 and $19($ median $=1)$ beetles and between 0 and $22($ median $=0)$ larvae were found in attacked seedlings. A further census of the same sites from August to October 1998 and March to May 1999 revealed no evidence of root borer attack, and only a few tens of dead seedlings were found. In some areas soil disturbance by emerging cicada larvae caused some seedling death. 
Intensive sampling plots were set up on Site 4, where the highest incidence of root-borer attack had been found. Altogether 1173 Parashorea seedlings were removed from the large plot, and 554 from the small plot, giving 1727 seedlings in total. More than three-quarters of all seedlings were either dead or showed signs of wilting (Table 2). Almost half of all seedlings were found to be attacked, though this varied significantly with the health of the seedling (logistic regression, $\mathrm{P}<0.0001$ ). The proportion of seedlings attacked decreased with seedling vigour (Table 2).

\section{Experimental investigation of drought-herbivore interactions}

There was far greater mortality due to root damage in the dry plots than in any other treatment combination (Figure 2). The interaction between water availability and treatment was significant (loglinear analysis, $\mathrm{P}=0.02)$. Survival after root damage in the dry plots was only $8 \%$, whereas other treatments showed more than $80 \%$ survival. Dead seedlings that remained intact were examined for signs of herbivore damage. In the first census period 6 of 19 dead seedlings examined showed evidence of attack by root borers. These were found in two of the four blocks. In the second census, none of four seedlings examined showed evidence of attack. No data could be obtained from Site 4 wet plot on the third census because a fallen branch had crushed it.

Some seedling growth occurred during the experiment, though the mean growth rate was very low (Table 3). No significant differences were found between treatments (analysis of variance, $\mathrm{P}>0.05$ ), and only the wet Control seedlings showed RMHI significantly greater than zero (t-test, $\mathrm{P}<0.01$ ). RMLL and RMLG distributions were highly skewed, with most seedlings neither flushing nor losing leaves (Table 3). Leaf gain was significantly greater in

Table 1. Results of dead seedling censuses conducted in February-May 1998 (G1), August-October 1998 (C2) and March-May 1999 (C3).

\begin{tabular}{|c|c|c|c|c|c|c|c|}
\hline \multirow[t]{2}{*}{ Site } & \multirow[t]{2}{*}{ Species } & \multicolumn{3}{|c|}{ Dead seedlings found } & \multicolumn{3}{|c|}{$\%$ Attacked } \\
\hline & & C 1 & C2 & C3 & Gl & C2 & C3 \\
\hline East Trail & Parashorea spp. & 20 & 0 & 0 & 30 & 0 & 0 \\
\hline Nature Trail & Parashorea spp. & 23 & 0 & 0 & 9 & 0 & 0 \\
\hline Site 4 & Parashorea spp. & 37 & 16 & 0 & 86 & 0 & 0 \\
\hline Site 1 & Parashorea spp. & 102 & 11 & 0 & 34 & 0 & 0 \\
\hline West Trail & Parashorea spp. & 5 & 0 & 0 & 40 & 0 & 0 \\
\hline Tembaling Trail & S. johorensis & 25 & 0 & 0 & 24 & 0 & 0 \\
\hline
\end{tabular}

Table 2. Incidence of root borer attack by seedling vigour. Pooled data from large and small sampling plots.

\begin{tabular}{lcc}
\hline Status & Number & \% Attacked \\
\hline Healthy & 386 & 31 \\
Partly wilted & 371 & 35 \\
Fully wilted & 415 & 47 \\
Dead & 555 & 67 \\
\hline
\end{tabular}




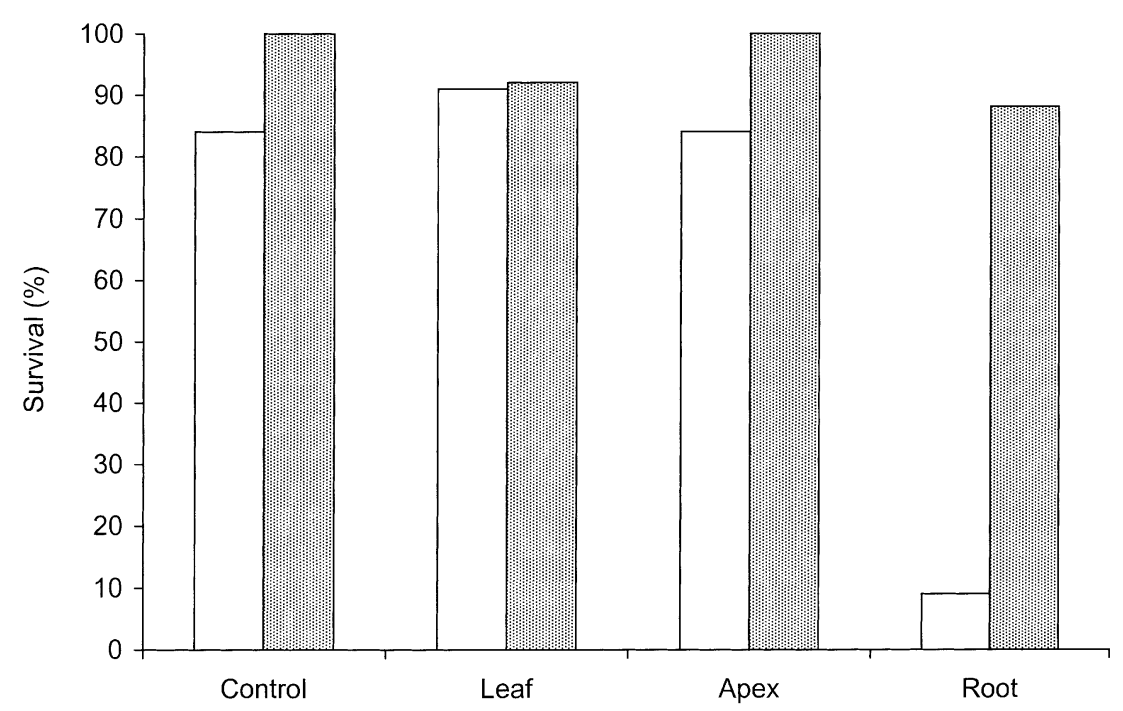

Figure 2. Percentage survival by damage treatment for dry (open bars) and wet (shaded bars) plots. Pooled data for four blocks. Damage was artificially imposed.

dry plot seedlings for all treatments except root damage (Mann-Whitney tests, $\mathrm{P}<0.05)$. Regrowth from secondary meristems was significantly more common in those seedlings that had their apical meristems removed than in control seedlings (Table 3 , logistic regression, $\mathrm{P}<0.05$ ).

\section{DISGUSSION}

The root-borer outbreak provides some support for the plant stress hypothesis, since it was observed at the end of a strong El Niño-induced drought, attack was related to seedling vigour, the highest level of infestation was found in a site where many seedlings were wilting under drought stress, and no root borers were found in seedlings surveyed after the drought had passed. Infestation of apparently healthy seedlings should not be taken as evidence for the plant vigour hypothesis, since seedlings may have been stressed without showing obvious symptoms. Furthermore, healthy seedlings may not have been spatially independent of nearby infested seedlings, and so could have been attacked despite their greater resistance or lower suitability to the beetles. Scolytid beetles are known preferentially to attack drought-stressed trees (examples in Berryman 1988). South-East Asian scolytids have life cycles of only a few weeks (Chey 1996), allowing very rapid population growth and the potential for outbreaks. The genus Xyleborus has a worldwide distribution, and is a common timber pest in South-East Asia (Anon. 1950, Schedl 1958, Thapa 1970).

The beetle showed a high degree of preference for Parashorea despite the presence of other seedling species, though a small number of dead Shorea johorensis seedlings were found with evidence of root boring. In another study of 
Table 3. Growth and leaf turnover.

\begin{tabular}{|c|c|c|c|c|c|c|}
\hline & Treatment & $\mathrm{N}$ & $\begin{array}{c}\text { RMHI }\left(\times 10^{-3}\right) \\
\text { mean } \pm \mathrm{SE}\end{array}$ & $\begin{array}{c}\text { RMLG }\left(\times 10^{-3}\right) \\
\text { median } \\
(\mathrm{IQR})\end{array}$ & $\begin{array}{c}\text { RMLL }\left(\times 10^{-3}\right) \\
\text { median } \\
(\mathrm{IQR})\end{array}$ & $\begin{array}{l}\text { Shoot } \\
\text { regrowth }\end{array}$ \\
\hline \multirow[t]{4}{*}{ Dry } & Control & 27 & $2.0 \pm 1.2$ & $\begin{array}{c}83 \\
(51-125)\end{array}$ & $\begin{array}{c}0 \\
(0-0)\end{array}$ & $19 \%$ \\
\hline & Leaf & 29 & $0.0 \pm 1.4$ & $\begin{array}{c}63 \\
(26-115)\end{array}$ & $\begin{array}{c}0 \\
(0-0)\end{array}$ & $7 \%$ \\
\hline & Apex & 27 & $0.0 \pm 1.2$ & $\begin{array}{c}83 \\
(6-125)\end{array}$ & $\begin{array}{c}0 \\
(0-0)\end{array}$ & $44 \%$ \\
\hline & Root & 3 & $1.7 \pm 2.8$ & $\begin{array}{c}12 \\
\text { (na) }\end{array}$ & $\begin{array}{l}12 \\
\text { (na) }\end{array}$ & $33 \%$ \\
\hline \multirow[t]{4}{*}{ Wet } & Control & 24 & $2.2 \pm 0.8^{*}$ & $\begin{array}{c}39 \\
(0-56)\end{array}$ & $\begin{array}{c}0 \\
(0-17)\end{array}$ & $17 \%$ \\
\hline & Leaf & 22 & $1.0 \pm 0.6$ & $\begin{array}{c}33 \\
(22-56)\end{array}$ & $\begin{array}{c}0 \\
(0-12)\end{array}$ & $23 \%$ \\
\hline & Apex & 24 & $1.2 \pm 1.1$ & $\begin{array}{c}42 \\
(8-56)\end{array}$ & $\begin{array}{c}0 \\
(0-22)\end{array}$ & $33 \%$ \\
\hline & Root & 21 & $1.4 \pm 0.9$ & $\begin{array}{c}27 \\
(0-42)\end{array}$ & $\begin{array}{c}29 \\
(24-79)\end{array}$ & $24 \%$ \\
\hline
\end{tabular}

* Significantly greater than 0 at $\mathrm{P}<0.05$. RMHI, relative monthly height increment; RMLG, relative monthly leaf gain; RMLL, relative monthly leaf loss. Interquartile range (IQR) is given for RMLG and RMLL since the data have a strong right skew.

dipterocarp seedling growth in the Danum Valley, Parashorea was preferentially attacked by a grasshopper (Orthoptera) (Whitmore \& Brown 1996). The forest at Danum Valley has been described as Parashorea malaanonan type due to the prominence of this species among the large dipterocarps (Fox 1972), and it could be that some density-dependent mortality mechanism (sensu Connell 1978, Janzen 1970) is in operation.

The observed outbreak occurred over a large area of forest, the furthest affected sites being separated by over $2 \mathrm{~km}$. The outbreak was very patchily distributed, with some seedling populations apparently untouched, whilst others showed high levels of infestation. This patchy distribution has been noted in many soil herbivores (Brown \& Gange 1990), and may be due to the distribution of dry soils or infested adult trees harbouring beetle populations. Emigration from stressed 'focus' trees to nearby 'recipient' trees has been described in the spruce beetle Dendroctonus frontalis (Hard 1989). Since only one outbreak in one area of forest was observed, further examples and experimental manipulations are required to draw firm conclusions concerning the relationship between drought and root borer outbreaks. To detect future outbreaks, large-scale seedling surveys spanning several droughts are required. Studies of tree recruitment are many, but they emphasize a large number of samples within a small area and for a short time (Clark et al. 1999). At Danum, a relatively large-scale survey of seedling growth and survival was undertaken by Still (1992), though this only lasted for 2 y and did not investigate herbivory. Perhaps the increasing frequency of droughts and associated pest outbreaks will provide ample opportunities for such studies in the future.

Root herbivory was shown to be more detrimental to seedlings than either 
defoliation or apical meristem damage, but further experiments are necessary to prove that drought-stressed seedlings are more susceptible to attack by herbivores. Root herbivory is difficult to investigate and is often ignored, leading to a false conclusion that absence of evidence equals evidence of absence (Brown \& Gange 1990). Manipulative field experiments using soil insecticides (Brown \& Gange 1989a,b) may be used to exclude herbivores if the scale of heterogeneity of herbivore distribution is less than that of the experiment, otherwise the areas treated may be without herbivores anyway. Experimental manipulation of water availability and exposure to beetles (Dunn \& Lorio 1993) could be employed to determine unequivocally whether beetles preferentially attack stressed seedlings.

\section{ACKNOWLEDGEMENTS}

We acknowledge the following for permission to conduct research in the Danum Valley, Sabah: Yayasan Sabah (Forestry Upstream Division), The Danum Valley Management Committee, The State Secretary (Internal Affairs and Research Office), Sabah Chief Minister's Department, and the Economic Planning Unit of the Prime Minister's Department, Kuala Lumpur. We thank Dr Chey Vun Khen (Head of Entomology Division, Forest Research Centre, Sepilok, Malaysia) for assistance in field studies, Dr Ruth Ripley (Department of Statistics, University of Oxford) for statistical analyses, and three anonymous reviewers for comments on the manuscript. This paper is based on material collected whilst Daniel Bebber was a participant in The Royal Society's SE Asia Rainforest Research Programme (Programme Publication No A/304), project number 132, and Danum Valley Rainforest Research and Training Programme project number 151. The study was funded by the Burtt Davey Research Scholarship, University of Oxford, UK.

\section{LITERATURE CITED}

ANDERSON, J. A. R. 1961. The destruction of Shorea albida forest by an unidentified insect. Empire Forestry Review 40:19-29.

ANON. 1950. Bionomics of Scolytidae and Platypodidae. Report of the Forest Administration of Malaya 12. Forest Administration of Malaya, Kuala Lumpur. 12 pp.

BECKER, P. 1983. Effects of insect herbivory and artificial defoliation on survival of Shorea seedlings. Pp. 241-252 in Sutton, S. L., Whitmore, T. C. \& Chadwick, A. C. (eds). Tropical rain forest: ecology and management. Blackwell Scientific Publications, Oxford.

BERRYMAN, A. A. (ed.) 1988. Dynamics of forest insect populations. Plenum Press, New York. 603 pp.

BROWN, V. K. \& GANGE, A. C. 1989a. Differential effects of above- and below-ground insect herbivory during early plant succession. Oikos 54:67-76.

BROWN, V. K. \& GANGE, A. C. 1989b. Herbivory by soil-dwelling insects depresses plant species richness. Functional Ecology 3:667-671.

BROWN, V. K. \& GANGE, A. C. 1990. Insect herbivory below ground. Advances in Ecological Research 20:1-58.

CHEY, V. K. 1996. Forest pest insects in Sabah. Sabah Forest Department, Sandakan. 111 pp.

CLARK, J. S., BEGKAGE, B., GAMILl, P., GLEVELAND, B., HILlERISLAMBERS, J., LICHTER, J., MCLACHLAN, J., MOHAN, J. \& WYKLOFF, P. 1999. Interpreting recruitment limitation in forests. American Journal of Botany 86:1-16.

COLEY, P. D. 1998. Possible effects of climate change on plant/herbivore interactions in moist tropical forests. Climatic Change 39:455-472. 
CONNELL, J. H. 1978. Diversity in tropical rain forests and coral reefs. Science 199:1302-1310.

DAVIES, S. J. \& UNAM, L. 1999. Smoke-haze from the 1997 Indonesian forest fires: effects on pollution levels, local climate, atmospheric $\mathrm{CO}_{2}$ concentrations, and tree photosynthesis. Forest Ecology and Management 124:137-144.

DUNN, J. P. \& LORIO, P. L. 1993. Modified water regimes affect photosynthesis, xylem water potential, cambial growth, and resistance of juvenile Pinus taeda L. to Dendroctonus frontalis (Coleoptera: Scolytidae). Environmental Entomology 22:948-957.

FOX, J. E. D. 1972. The natural vegetation of Sabah and natural regeneration of dipterocarp forest. Ph.D. thesis, University of Wales.

HARD, J. S. 1989. Sequence of trees attacked by spruce beetles in a mature even-aged spruce stand in south-central Alaska. Northwest Science 63:5-12

HOFFMAN, A., HINRICHS, A. \& SIEGERT, F. 1999. Fire damage in East Kalimantan in 1997/98 related to land use and vegetation classes: Satellite radar inventory results and proposals for further actions. With contributions from G. Ruecker, L. Christy, and B. Yuliarso. Report No. 1. Sustainable Forest Management Project (SFMP) \& Integrated Forest Fire Management (IFFM) Project, Indonesian Ministry of Forests and Estate Crops (MoFEG) and German Technical Cooperation Agency (GTZ), Samarinda, Indonesia.

JANZEN, D. H. 1970. Herbivores and the number of tree species in tropical forests. American Naturalist 104:501-528.

KORICHEVA, J., LARSSON, S. \& HAUKIOJA, E. 1998. Insect performance on experimentally stressed woody plants: a meta analysis. Annual Review of Entomology 43:195-216.

MARKHAM, A. 1998. Special issue: potential impacts of climate change on tropical forest ecosystems. Climatic Change 39:141-143.

MARSH, G. \& GREER, A. G. 1992. Forest land-use in Sabah, Malaysia: an introduction to the Danum Valley. Philosophical Transactions of the Royal Society of London, Series B 335:331-340.

MATHSOFT 2000. S-Plus for Windows. Mathsoft Inc., Cambridge.

MATTSON, W. J. \& HAACK, R. A. 1987. The role of drought stress in provoking outbreaks of phytophagous insects. Pp. 365-407 in Barbosa, P. \& Schultz, J. C. (eds). Insect outbreaks. Academic Press, London.

MCPHADEN, M. 1999. Genesis and evolution of the 1997-1998 El Niño. Science 283:950-953.

MEIJER, W. \& WOOD, G. H. S. 1964. Dipterocarps of Sabah. Forest Department, Sandakan. 344 pp.

NAKAGAWA, M., TANAKA, K., NAKASHIZUKA, T., OHKUBO, T., KATO, T., MAEDA, T., SATO, K., Miguchi, H., NAGAmasu, H., OGinO, K., TEO, S., HAMID, A. A. \& LEE, H. S. 2000. Impact of severe drought associated with the 1997-8 El Nino in a tropical forest in Sarawak. Journal of Tropical Ecology 16:355-367.

PRICE, P. W. 1991. The plant vigor hypothesis and herbivore attack. Oikos 62:244-251.

SCHEDL, K. E. 1958. Bark and timber beetles from Malava. Malayan Forester 21:99-105.

SCHOWALTER, T. D., LIGHTFOOT, D. G. \& WHITFORD, W. G. 1999. Diversity of arthropod responses to host-plant water stress in a desert ecosystem in southern New Mexico. American Midland Naturalist 142:281-290.

SPSS 1999. SPSS for Windows 10. SPSS Inc., Chicago.

STILL, M. J. 1992. Population dynamics and spatial pattern of dipterocarp seedlings in a tropical rain forest. Ph.D. thesis, University of Stirling.

THAPA, R. S. 1970. Borers of freshly felled timbers of Parashorea tomentella and their control. Malayan Forester 33:230-239.

WALSH, R. P. D. 1996. Drought frequency changes in Sabah and adjacent parts of northern Borneo since the late nineteenth century and possible implications for tropical rain forest dynamics. Journal of Tropical Ecology 12:385-407.

WALSH, R. P. D. \& NEWBERY, D. M. 1999. The ecoclimatology of Danum, Sabah, in the context of the world's rainforest regions, with particular reference to dry periods and their impact. Philosophical Transactions of the Royal Society, London, Series B 354:1869-1883.

WARING, G. L. \& COBB, N. S. 1992. The impact of plant stress on herbivore population dynamics. Pp. 168-187 in Bernays, E. E. (ed.). Insect-plant interactions. GRC Press, Boca Raton.

WHITE, T. G. R. 1974. A hypothesis to explain the outbreaks of looper caterpillars, with special reference to populations of Selidosema suavis in a plantation of Pinus radiata in New Zealand. Oecologia 22:119-134.

WHITMORE, T. G. 1998. Potential impact of climatic change on tropical rain forest seedlings and forest regeneration. Climatic Change 39:429-438.

WHITMORE, T. G. \& BROWN, N. D. 1996. Dipterocarp seedling growth in rain forest canopy gaps during six and a half years. Philosophical Transactions of the Royal Society, London, Series B 351:11951203.

WOLTER, K. \& TIMLIN, M. S. 1998. Measuring the strength of ENSO - how does 1997/98 rank? Weather 53:315-324. 